have watched the exit of the lens without seeing this; indeed, the wonder is that this delicate membrane should ever regain its position and function. Mr. Jeafreson likens this unnatural proceeding to normal parturition, and compares the methods which have been happily devised by von Graefe and others to escape this serious danger, and which experience has proved to be so eminently successful, to the Crsarean section! No operator of experience can bave failed to appreciate the dangers to which $I$ have alluded, and which skill cannot avoid. In fact, it is well known that they have led to the practical abandonment of the flap method of extraction, and the almost universal adoption, both ${ }_{i x}^{r y}$ at horne and abroad, of von Graefe's, Mooren's, my own, and other modes of extracting, which, although singularly safe, involved the sacrifice of a segment of iris, and, consequently, more or less cosmetic defect, dazzling, and defective accommodation.

The occasional reversion to the old flap method, in spite of its attendant dangers, is only an expression of that intense longing which every conscientious operator must feel to accomplish extraction safely without mutilating the pupil; and it occurred to me that this end might be attained, combined with all the safety of modern methods of extracting, by merely limiting the iridectomy to the periphery of the iris, or simply separating it from its marginal attachment, either by incision or dialysis, so as to obviate the risk of prolapse, and yet maintain the pupil in all its integrity, thus securing the chief advantage of Danell's method without its attendant dangers. And I must say that the hopes which I entertained as to the results to be ob. tained have been fully justified by experience; for, since devising this method, I have operated on twenty-nine eyes in succession without any selection whatever, some of the patients being of great age-one eighty-three, and others more or less unfavourable subjects-and have not, altogether, lost one of them. It is true that some have remain of capsule, which will require treating; that two have bad jritis with closed pupils, which admit of remedy; and three, owing to prolapse of the vitreous, occasioned by straining of patients operated on without chloroform- present artificial pupils beside the natural one-a condition which $I$ intend to treat either by iridectomy, enclavement, or iridodesis. Mr. Jeaffreson remarks, "That every step of my operation is performed with difficulty and attended with danger, and when the operation is completed a double pupil is left." But, in point of fact, when successfully carried out there is no second pupil; a slight puckering, which is not remarked even when the lower section is adopted, is often all that remains. And even when the iris continues separated from its border, as in those cases where prolapse of the vitreous occurred, the slight gap is not seen if the other section is selected. The patient I introduced to the members of the Ophthalmological Congress at the College of Physicians had undergone double extraction-one by the flap method, the other by my peripheral section. Both were successful. The patient had large prominent eyes, and there was no deformity whatever in either. I don't deny that the operation is diffeult, nor do $I$ say that $I$ would select it in every case; but it is certainly not exceptionally dangerous, as events have proved. Indeed, I am inclined to think that very little injury is inflicted on the eye by this method, and that it is followed by less irritation than is usually observed after removal of the lens, an observation I find confirmed by the experience of Mr. Carter, of St. George's, who has adopted it. This I attribute to the fact that there is no stretching of the pupillary aperture during the escape of the lens, no bruising of that portion of iris which initiates inflammatory reaction in so many cases of flap; no dragging of the iris during the excision of the minute portions-not bigger than a fly's eye-which it is necessary to remove; and no hæmorrbage from wounded iris into the anterior chamber to obscure the subsequent steps of the operation or form irritating clots after it.

I intend shortly to introduce a number of patients on whom I have operated by this method to one of the metropolitan medical societies. I shall also endeavour on the same day to perform the operation, when I trust Mr. Jeaffreson will be able to honour me with his presence.

I am, Sir, your obedient servant,

C. BeLl TAYLoR, M.D., F.R.C.S.E. Surgeon to the Nottingham and Midland Ese Infirmary.

\section{AN ESTHETICS.}

To the Editor of THE LANCET.

SIR,-Much has been written on the above subject recently of the greatest possible interest. From what I have read my strong impression still is that the occasional bad results are not due positively to the anæsthetic itself, but negatively to the sudden absence of oxygen occurring inadvertently in the course of administration of the agent, notwithstanding the ingenious methods employed. In many of the fatal cases recorded the means used were of the rudest kind-such, for instance, as pouring the agent on a towel or piece of lint and therewith covering the mouth and nostrils at once with it. The question one asks in that case is, how is oxygen to get to the heart, the two external apertures by which it commonly enters being blocked? I for one feel perfectly satisfied as to the cause in case of a fatal result under such circumstances. The chloroform gas occupies all the air-passages to the exclusion of the atmosphere, and consequently of oxygen, and the patient is at once in danger of being asphyxiated. Again, the machines used purposely to admit the common air pari passu with the gaseous agent may occasionally imperfectly effect the object. In either case the result would be the same, from the same cause. What seems confirmatory of this view is the fact that, as dangerous symptoms intervene, the operator at once draws out the tongue, perhaps blows down the trachea, works the walls of the chest, and does everything possible to cause air to be inspired, the inference being that the heart wants air and oxygen, not that the anæsthetic agent itself wants an antidote.

Holding these views, years ago I advocated in your pages the administration of chloroform by one aperture onlythe mouth-always leaving the nostrils entirely free for the admission of air in the usual way. The operation would be longer about, but I will venture to say it would be much safer. One other suggestion I would offer. Could oxygen gas be by any means, in a certain proportion, commingled with chloroform, so that the two gaseous bodies should pass simultaneously into the system without neutralising in any respect the anæsthetic effects of the latter agent? Possibly this notion may be considered crude by the highly scientific. I would, however, remark that I do not understand the more perfect safety of the nitrous oxide gas, except that it conveys more free oxygen into the system when inspired. Probably, also, etherisation has some small advantage over chloroform in this respect, but not enough to make it perfectly safe as an anæsthetic. I am, Sir, yours, \&a.,

Geo. Bodington, Sen., L.R.C.P.E.

Rocksall, Sutton Coldfield, Dec. 1872 .

\section{PLUGGING THE POSTERIOR NARES.}

\section{To the Editor of THe LANCET.}

SIR,-In reply to a letter signed by "A. G." in THE LANCET of December 21st, which I have seen only to-day, I hasten to inform him that Messrs. Weiss, at my request, have had manufactured some nasal-bag plugs such as he describes, and will be happy to supply him with some for trial. I also beg to forward to you a short account of this nasal.bag plug, which I have had by me for some time past, and delayed publishing. Some weeks back I read this account to $\mathrm{my}$ friend Mr. Thomas Moore of Petersfield, Hants, and exhibited the nasal-bag plugs to Mr. E. Young of Steyning, Sussex, and Mr. G. Tatham of Brighton. If you will kindly publish the description I shall feel much obliged. I am glad to find that the same idea has occurred to "A. G.," and feel more confident in forwarding the enclosed description of the nasal-bag plug for publication.

A Method of Plugging the Posterior Nares from the Anterior Nares.-Having on several occasions had to plug the posterior nares for epistaxis, and having once or twice (owing to the peculiar formation of the parts at the back of the mouth and fauces) found great difficulty in drawing up the plug from the mouth into the posterior nares, and having to use some force with the finger to push the plug up behind the soft palate, it struck me that a method might be adopted whereby the posterior could be plugged from the anterior nares, and so aroid the inconvenience and 